\title{
Is There Time Enough? Temporal Resources and Service Performance in the Danish Home Care Sector
}

\section{Pernille Tufte}

PhD. student, Department of Society and Globalisation, Roskilde University, Denmark ${ }^{1}$

\begin{abstract}
Reflecting on the temporal conditions of home care work, care workers are fairly critical, stressing that time frames are inflexible and time is limited and occasionally insufficient, altogether constituting a time pressure in work performance. Besides from the immediate consequences of time scarcity in the daily work performance, care workers relate the issue of time to a more fundamental discussion of what the performance of care does and should entail. The purpose of the article is to examine care workers' perceptions of the temporal conditions of care work, investigating how time pressure constitutes a challenge to care workers' own sense and valuation of their work. The article is informed by two theoretical perspectives: standardization of care services and performance of care work in private homes. Empirically, the article examines how care workers perceive the relations between the temporal framing and the possibilities to perform care work. Methodologically, the article is based on qualitative data, collected through focus group interviews and participant observation, and analyzed within the perspective of reflexive interpretation, using grounded theory method and hermeneutic approaches of analysis. A central focus of analysis is the concept of "additional care services." The use of the concept reflects different understandings of care. Relying on the logic of standardization, managers articulate additional services as definite items, which could (and should) be left out of the performance of care work. Care workers do, however, not accept this notion. Relying on their experience of work, they perceive additional services as an ambiguous concept, which recognizes the multiple character of care work. Conclusions are that time scarcity constitutes a pressure on work performance as a whole, reducing care workers' flexibility, challenging their authority, but still keeping them in a position of responsibility. Ultimately, the battle on time reflects the ambivalences in care work-ambivalences that are becoming increasingly difficult for care workers to handle in work performance.
\end{abstract}

\section{KEYWORDS}

Time / home care / work performance / care services

\section{Time as a constraint in work performance}

I: Would it be better, if you had more time?

Several respondents: Yes, absolutely

I: But where should you draw the line? How much time should you spend with them?

R1: You cannot generalize

R2: There has to be flexibility. (We only ask for) more time, if it is needed. Not in general, but only if the need is there. It is not about more time for coffee.

\footnotetext{
${ }^{1}$ Pernille Tufte, PhD. student, Department of Society and Globalisation, Roskilde University, Denmark. Email: pjt@ruc.dk
} 
The temporal framing of care work is decisive. The availability of time constitutes the fundamental basis for provision of care services, whereas lack of time, conversely, constitutes an immediate barrier for service provision. Home care work is performed according to a daily work schedule, indicating the services to provide at each care visit and the expected duration of the visits. Every type of care service elicits a fixed amount of minutes, determined by the municipal quality standards. Based on these assessments, the expected duration of a visit is calculated.

It is a general experience among care workers in this study that the allocation of time to a varying degree equals the need of time on the particular care visits. On some visits, the available time is sufficient, while on other visits there is a discrepancy between the tasks to perform and the time available to do it, implying either a surplus of time or, more frequently, time insufficiency. As exemplified by the quotation, care workers ask for more time in work performance-not as an indication of general time scarcity, but as an indication of time, being occasionally scarce. Thus, the request for more time reflects the conditions under which care work is performed, revealing the unpredictable and complex character of care work.

In practice, care workers often apply a flexible approach to the division and use of time. Entering the home of an elderly person, the care worker may find the elderly being either noncooperative, ill, or in a bad mood, wanting or being in need of other services than the ones defined in the work schedule-and consequently more time is required. Aiming at adapting the performance of work to the current needs and everyday life situation of the elderly, care workers may divide the time available between the elderly differently than indicated in the work schedule. Consequently, some care visits last longer than planned, while others are shorter.

Still, a flexible approach to the unpredictable character of care work is subject to uncertainty, emphasizing a constant consideration and judgment of the care workers. If taking care of an elderly person requires more time than allocated, care workers may include any available surplus of time. If no previous care visits have resulted in a surplus of time, care workers are however forced to "steel" time from other care visits, requiring that they work faster, postpone tasks, or call for assistance from colleagues. In any case, in order to maintain flexibility in care work performance, a temporal room for maneuver is needed.

R: 'I have a client who gets 18 minutes to eat'.

R: 'A client has to get out of bed, sit on the pelvic chair and have a meal served-in 17 minutes'.

These quotations reflect the temporal premises of care work, underlining the correlation between tasks and time. They clearly illustrate the fact that every (group of) task elicits a specific amount of minutes, not indicating that the allocation of minutes is too limited per se, but rather implying that the whole premise of care work planning is untenable. The temporal planning is in its essence rigid, specifying precise indications of time for every care visit. Care workers express vulnerability in relation to that part of the work structure, leaving them in a (occasionally difficult) position of altering the temporal framing in practice. As the Danish elder care sector recently has implemented financial cutbacks, also resulting in reductions of time for service provision, care workers find that this pattern has become even more difficult to enforce. Expressing their concerns of 
(occasional) time pressure and time insufficiency in work performance, care workers are confronted by care managers with the possible solution of leaving out additional care services of the performance. Care workers oppose to this solution, perceiving it to be difficult to enforce and a challenge to the kind of care they aim to perform.

The purpose of this article is to examine care workers' perception of the main challenges in relation to time and care, investigating how time pressure touches upon the essential subject of what care is. More specifically, the article aims at analyzing the notion of service division, outlining the different understandings of the concept and the implications on the performance of care work. The problem of service division touches upon the split between the simple notion of time availability, assessed by a number of minutes, and the complexity of care work performance, implying a more flexible approach to the temporal conditions. This dilemma, exemplified by theoretical understandings on standardization and care in private homes, constitutes an overall perspective of the analysis of service division and the implications on work performance in this article.

The structure of the article implies a presentation of relevant studies, framing this particular article, and a section presenting the data and methods used. The main theoretical perspectives are introduced, supporting the empirical analyses of the article, discussing the perceptions and implications of the division of care services, and outlining some of the related challenges on content and performance of care work.

\section{Time and care: dilemmas and division of services}

All work is temporally structured. Time schedules are necessary for efficient work performance (Fine 1990). People sell their labor power, making it available for a certain amount of time, and efficiency depends on the output of the workers in this limited amount of time (Cohen 2011). Also home care work is timed work. It is characterized by a rationalized organizational structure, which calls for a strict temporal order. The work day begins and ends at fixed, predefined hours and the content and the allocated time for every care visit is defined in the daily work schedule. However, home care work is performed in the private homes of the elderly, leaving care workers in a position of interacting with the elderly within the temporal framing of their everyday life situation. These temporal frames of care work are supported by two predominant logics of time, clock time and process time. Clock time (Adam 1990, 1995; Davies 1994; Eriksen 2002) signifies a linear, standardized, and invariable measurement of the time, whereas process time (Bryson 2007; Davies 1994; Twigg 2000) signifies time as being internal in social lives, a personal experience and dependent on context. In practice, these logics of time may diverge. When the logic of clock time prevails, work rhythms are (allegedly) not dependent on the particular conditions and needs of the context (Adam 1990), and the different logics of time altogether constitutes temporal dilemmas in the performance of home care work.

A critical approach to the temporal dilemmas in care work is expressed by Andersson (2008), emphasizing that time is neglected and made invisible by care managers and policy makers. These levels of the care organization focus primarily on the help activities, associating the planning process with the understanding of clock time. Less focus is put on the social context, within which the activities are performed and which is associated with the understanding of process time. This dilemma leads Andersson to conclude 
that the time spent on care visits is partly invisible. Findings of this study also show that downsizing and new forms of organization have increased time pressure in elder care. Findings of the study, having been conducted in the Swedish elder care sector, may not be fully transmittable to a Danish context, as financial cutbacks in the public sector have been relatively more widespread in Sweden. However, since cutbacks have been implemented in the Danish care sector during the past years, similar tendencies are now showing in Denmark. Andersson concludes that downsizing is problematic, not only in terms of time availability but also just as important because part of time spent on care work has been made insignificant and invisible.

Focusing on time in care work and more specifically applying the logics of time as analytical perspectives are relevant approaches to expose and understand the ambiguous and complex character of care work. However, other perspectives do equally assess the essential dilemmas of care work, focusing more explicitly on the organizational structure and the content and purpose of care.

For the past decade, home care work in Denmark has been organized by the purchaser-provider model, a new public management-inspired organizational model. The purchaser-provider model signifies a split between the assessment of needs and definition of services, performed by purchasers, and the provision of services, performed by care workers. Being closely related to the introduction of another political initiative (the free choice of service provider) the purchaser-provider model concerns efficiency, marketization, and care services as a welfare state right, emphasizing transparency and standardized care services (Dahl 2009). Having divided needs assessment, definition of tasks, and planning of care work from the provision of services, the purchaser-provider model holds an implicit ambivalence. Following the idea of the model, care workers are to provide services, which are all defined in standardized terms. Obviously, the services are defined on the basis of an assessment of the elderly persons' current needs and situation (purchasers' needs assessment), but it is the responsibility of the care workers, on a daily basis, to convert the services into practice. Given that the provision of services takes place in a private home context, service provision is a matter of considering and adjusting to individual, changeable, and unpredictable life settings.

A number of studies have addressed the dilemma of adapting standardized services to particular and personal life situations, highlighting the contrasting logics of care and planning (Mol 2008; Waerness 1984), the paradoxes of standardized regulation of care work vs. complexity of work performance (Bjôrnsdottir 2012; Dahl \& Rasmussen 2011; Vabø 2007), and especially focusing on the performance of care workers-how they navigate and negotiate the conditions of work in order to perform ethical and meaningful care (Dyck \& England 2012; Kirchhoff 2010).

In focusing on the dilemmas in relation to performance of care work, the lastmentioned studies have specifically focused on the issue of division of services. Having conducted a study in the Norwegian home care sector, Kirchhoff has identified a clear division between formal and hidden care services, the formal being the practical and predefined services and the hidden being the services that are not part of the formal work contract, unwanted by managers and performed in care workers' spare time. Kirchhoff concludes that the formal services are monotonous, demotivating, and a strain to care workers, whereas the hidden services, also termed as the private work relations, signify substance and meaning in work performance. 
In their analysis of home care work, Dyck and England use the classic dichotomy caring for (the physical tasks) vs. caring about (the relational and emotional dimensions of care work) as the basis of discussing the ambivalences of home care work today. Though recognizing that the caring for-caring about dichotomy primarily serves as an analytical separation, as they overlap empirically, the authors define work contracts and the emotional dimensions of care as two different categories, which (together with the materiality of the home as the third category) constitute ethical care. In practice, home care performance is constituted by care workers, negotiating work regulations and bringing a little "extra" into the care relation, defining this extra as "texturing a care relationship in ways not envisaged in the formal concept of care, assumed by rules and regulations, based on the notion of caring for without the dimension of caring about" (Dyck \& England 2012, p.74).

This particular study places itself within the framework of the presented research, relying on the understanding of care work performance being characterized by temporal dilemmas as well as dilemmas regarding the tasks and context of the performance. Especially the clear distinctions between predefined and additional care services, stressing a division between physical and practical tasks, based on work contracts and regulations, and the emotional dimensions of care work, defined as a distinct subject and a matter of care workers' own initiative and responsibility to include in work performance, are of relevance to this study.

Whereas these studies have pointed out different characteristics of the dilemmas in care work, this study aims, however, to elaborate further on the dilemmas and their consequences in care work performance, especially focusing on the issue of service division. As already indicated in the empirical introduction to this article, care workers in this study oppose to the division between predefined and additional services, perceiving the separation of the predefined/practical and additional/emotional aspects to be a construct that does not fully reflect the realities of home care work performance. Consequently, it is the intention of this study to examine how the temporal framing affects and challenges care workers' perceptions of care and their possibilities to perform care work.

\section{Data and methods used}

The article is based on a qualitative field work, collected in the local home care sector in two Danish municipalities in 2010. The selection of cases is an important part of doing qualitative research, characterized by carrying through in-depth studies of single cases. Case selection in this study followed (partly) the strategy of maximum variation, aiming at securing variation in one dimension, i.e., size, localization, or organization, in order to identify and describe particular topics and patterns (Flybbjerg 1991; Neergaard 2007). Applying the perspective of the care workers and especially focusing on the performance of home care work, cases were intended to represent a variety of work situations in order to provide the best possible knowledge on home care performance. Geographic setting was chosen as a relevant parameter in terms of variance, considering that the private homes of the elderly constitute principal conditions of home care work and assuming that different physical localizations of habitat-and the lives that are lived here-signify different conditions of work. Consequently, two 
municipalities were selected: a large, provincial municipality, covering both urban and rural areas and employing about 1,500 people in the local elder care sector, and a small, urban municipality, employing about 300 people in the local elder care sector. Two work units from each municipality participated in the study (the size of each work unit varied from 15 to 25 employees). The data, used in this study, derive from observation and focus group interviews in these four work units. Two focus group interviews with six participants were conducted in each municipality, including care workers from different positions and from different work units. Participant observation was conducted in three of the four work units, 1 week in each unit. During that period, I followed eight different care workers and visited the homes of 69 elderly people (a total of almost 100 visits).

In this article, I use the term "care workers" for people working in the elder care sector. In Denmark, care workers are divided into three professions: the social and healthcare helpers (1 $1 \frac{1}{2}$-year education), the social and healthcare assistants (3-year education), and nurses (4-year education). Social and healthcare helpers constitute the majority of the employees. A main reason for using the unifying term care workers is that this study is not a comparative study, but rather a study that aims at investigating phenomena and practices across the professions. Another reason is that social and healthcare helpers and assistants are particular Danish terms, which do not correspond with division of care workers elsewhere-rather, the term care worker seems to be widely applied internationally.

Requiring knowledge on care workers' reflections on the care work and the conditions under which it is performed, focus group interviews were applied as a main method in data collection. Emphasizing the formation of meanings and dynamics in groups (Halkier 2002; Steyaert \& Bouwen 2004), four focus group interviews were conducted, touching upon open and general topics like how they would describe their work and how they would define the ideal workplace, but also discussing more specific topics like the values and meaning of care work. Participant observation was applied as the other method of data collection. This method is relevant in the study of naturally occurring events, exploring the behavior and actions among people in given situations and gaining knowledge of their feelings and interpretations related to these actions (Waddington 2004). The purpose was to gain knowledge on work performance "in the making" and acquiring a more thorough understanding of work content, work routines, and different kinds of interaction between care workers and the elderly.

Analysis of the data was inspired by grounded theory method and the reflexive interpretation approach (Alvesson \& Sköldberg 2000; Charmaz 2003, 2006). Open and focused coding processes are central aspects of the grounded theory method and were used in the initial stages of data analysis. Coding is the process of defining what the data are about - on the basis of the data, concepts and categories are defined (Charmaz 2003; Strauss \& Corbin 1998). Using an open coding process, analyses are very detailed, outlining (basically) what people are saying and doing. Focusing on the context of the statements and actions is equally part of the analysis, looking for information on the conditions and consequences of what is said and done. In this particular study, the empirical data consisted in transcribed focus group interviews and field notes from observation studies.

The purpose of open coding is to generate strong analytic directions, leading to the next phase, the focused coding, which aims at assessing which codes best capture what is happening in your data and consequently raising them into conceptual categories 
(Charmaz 2003). In this study, the open coding process identified a large number of topics, relating to content, performance, and meaning of care work. In this process, time was identified as a central aspect, thus becoming a subject for further analysis in the focused coding process. The focused coding process, primarily being performed in the interview data, resulted in concepts, eventually categories, concerning the discussions, opinions, and implications of the temporal conditions of work.

At this point of analysis, I found it useful to include reflexive interpretation as a methodological approach in the study. The point of reflexive interpretation is for the researcher to take a relative stance to interpretation-to avoid getting stuck in a certain kind of logic of analysis, i.e., the empirical or the hermeneutic (Alvesson \& Sköldberg 2000). The hermeneutic perspective is relevant in the analysis of the performance of care work, emphasizing the relations between the individual care visits (the parts) and the general character of work performance/care work as a practice (the whole). In order to enhance the understanding of the framing and ambivalences in care work practices, I have included the theoretical perspectives of standardization (Bjôrnsdottir 2012; Timmermans \& Almeling 2009; Timmermans \& Epstein 2010) and care in private homes (Twigg 1997, $1999,2000)$ in the analyses. These perspectives have consequently informed the analyses of how care workers perceive the principal dilemmas of care work performance and how the performance is affected by the temporal conditions of care work.

\section{Standardization of elder care in Denmark}

The standardization of care work and the realities of the elderlys' homes are predominant in the framing and actual performance of home care. These perspectives are presented more thoroughly in this section, constituting the frame of analysis of time pressure and challenges of care.

Home care work has been increasingly standardized throughout Western societies (Bjôrnsdottir 2012; Purkis et al. 2008; Trydegård 2012). Standardization can be defined as a process of constructing uniformities across time and space (Timmermans \& Epstein 2010), emphasizing elements such as predictability, efficiency, accountability, and objectivity. A standardized provision of care services is consequently a procedure that can be identified and applied universally, securing uniformity and preventing favoritism toward particular clients. Addressing the drawbacks of standardization of care work, researchers have pointed to the process of depersonalization of care, the replacement of holistic care with bureaucratic control, and the formalization of work performance, reducing the flexibility and ability to respond to the unique needs of the elderly (Purkis et al. 2008; Timmermans \& Almeling 2009). Furthermore, the purchaser-provider model holds elements of distrust, as the central assessment of needs is removing the individual judgments - and hereby undermining the professionalization—of care workers (Dahl \& Rasmussen 2011).

In the Danish home care sector, standardization emerges in various forms: in the municipal formulation of quality standards of care services, in the assessment of the elderly persons' functional level and needs for care, and in the definition of the care services assigned to the elderly. The quality standards define the standards of care services, informing on the criteria for receiving elder care and specifying the kinds of care services that are available in each municipality. The purpose of the quality standards is for the 
municipality to be able to offer a uniform and high-quality service, considering the needs for care and the legal rights of the elderly (servicestyrelsen.dk). The assessment of needs and the decisions on allocation of care services are made by purchasers (compare with the purchaser-provider model). Having defined the particular care services allocated to the elderly persons, these services do, together with the allocation of time, constitute the main elements in the work schedules, on the basis of which care workers carry out the home care visits.

How the care services are defined in the work schedule may differ locally, though. In some municipalities, services are defined as packages, i.e., as a "morning package," containing a number of different services that may be provided. Other municipalities define in more detail the services to be provided. But although differing in specificity, the standardization concerns the definition of the specific types of service, i.e., preparing breakfast, washing, bathing, or assisting the elderly in getting dressed. In addition to the definition of work tasks, care work is equally framed by time, and the daily work schedules contain precise indications of time, allocated for each care visit. As such, the indications of time, along with the definitions of tasks, form part of the organizational structure of care work performance, constituting the standardized frame of the realization of the care visits.

Regarding standardization of care services from the care workers' perspective, it can be argued that work tasks may be defined in standardized terms, but how the tasks should be performed - the actual content of the work-is not defined in the work schedules. This view is supported by Vabø (2007), who states that work schedules do not contain instructions on work performance. Though working within a frame of standardized tasks, it is the responsibility of the care workers to give content to the frame.

\section{Care in private homes}

Julia Twigg, British sociologist, has done extensive research in the fields of care, ageing, and embodiment (Twigg 1997, 2000). As a central perspective in her research on care work, she has addressed the private and intimate aspects of the elderlys' lives, especially focusing on care of the bodies. Though written in an English context, which differs considerably from the Danish context in terms of organization, conditions, and care work as a profession, the work of Twigg still represents universal aspects of the character of work and work patterns in home care, which are relevant in analyses of the Danish home care sector.

Claiming that the institutional framework has been the dominant approach in research on care work, Twigg has conducted research on what she defines as the core of care work, the management of the body. The process of body management includes body work as well as emotional labor, requiring the care worker to respond to the specifics of the everyday situation of the elderly in the performance of care work (Twigg 2000). Emphasizing the elderlys' everyday life situations as the context and content of care work, Twigg has pointed out two principal characteristics of care work. One is recognizing declining physical capacities as the main objects of care work. The elderly have (to varying extent) lost control over their body and are no longer able to perform the personal chores that adults normally do by and for themselves. They now need assistance with a number of the daily chores like getting in and out of bed, eating, 
washing, bathing, and getting dressed. These chores may be regarded as ordinary and mundane in an everyday discourse, but being part of care work performance, care workers enter a very private sphere of other people. The personal caretaking of others includes closeness, touching, and intimacy, involving a transgression of the normal boundaries of adult life (Twigg 2000). These processes become central elements of care work performance, though hereby, according to Twigg, dissolving the ordinary. The other main characteristic is the interactional aspects of home care work. Viewing care work performance as production as well as consumption, the interaction is essential in performance. Care services are not provided in a vacuum, but performed in interaction between provider and recipient.

Bathing is an example of a care service that is provided because the elderly person no longer is capable of taking a bath himself or herself, and it is a care service that can be characterized as an interactional process. It is a practical activity, but the implementation of the activity requires personal engagement and involves intimacy, placing itself in the interface between the skilled and the natural. According to Twigg, bathing and washing is no straightforward, universal, or commonsense procedure. Rather, it is a care service of ambiguous character, being both subject to commercial (public) production and a service which aims at providing/assisting with chores that the elderly would normally do for themselves (Twigg 1997).

Including standardization and care in private homes as theoretical perspectives aimed at improving the understanding of what constitute the complex realities of care work. Planning/schedules/time measures on the one side and processes, interactions, and individual everyday life situations on the other constitute the dilemmas which are present in care work performance and therefore useful in order to understand care workers' perceptions of the conditions and challenges of care work.

\section{Predefined vs. additional services-a real dichotomy in home care work?}

Experiences of time pressure are related to the temporal conditions of care work in general, but newly executed time reductions have intensified these experiences, making it more difficult to perform tasks within the allocated time and to respond to the changing needs and unpredictable situations of the elderly. In the following, I will give a short introduction to the recent development in the two municipalities participating in the study-a development which has influenced the present temporal conditions of care work. While economic cutbacks have been on the agenda in the public elder care sectors throughout Western societies in the past decade(s), it is a relatively new phenomenon in Denmark (Burau \& Dahl 2012). In the two municipalities, economic cutbacks were executed during 2010, consequently being relatively newly executed when the fieldwork was conducted during the summer and fall of 2010.

In both municipalities, cutbacks have resulted in the dismissal of care workers, redefinition of services, removal of services from the service catalog (catalog of possible services to be provided), and reduced time for task provision. Cleaning services are (as well as personal care services) assigned in packages, and the time allocated for a cleaning package has been reduced. The quotation on the cleaning tasks, stated above, points out different implications of the reduction in time: that care workers have to 
speed up work pace, and that the rigid calculation of time builds on presumption which is not always present (referring to the cooperation of the elderly). Furthermore, given that the time available for each visit is not known to the elderly, care workers are left with the responsibility of providing a satisfactory service within a reduced time frame.

The time allocated for personal care services has been reduced as well, though the interpretations of these reductions differ. According to managers of the care units (as rendered by care workers), time reductions only affect "surplus time." By "surplus time," managers indicate that previously, the time allocated for every visit has been plentiful, and that time reductions only concern "additional services"- not the services assigned and defined in the work schedule. Following the argument of managers, consequences of reducing time for personal care services are that the allocation of time allegedly complies with the services to be provided. To adjust to the new amount of time, care workers are told to leave out additional services from care performance.

R1: Things may be so rigid that we overlook something.

R5: If they go through with making everything so rigid, I think they will loose a lot of us.

I: How is it getting rigid?

R5: We have been told that we are only supposed to do what the schedule says.

R1: That is what we are told in the mornings-only do what the schedule says.

R6: 'This is not a welfare office'.

The term "additional service" does in practice have several meanings, as the tasks, the needs, and the possibilities of every unique care situation differ. Understanding "additional" as everything that is not defined in the daily work schedules, a range of services may be taken into account, from bathing and washing, making the bed, doing the laundry, or taking out the garbage to smaller doings: "having a little talk, comforting, looking at a scratch, checking if the grocery bill is correct, making a nose trimmer work, or remembering the anniversary of the spouse's death." These are all examples of chores that care workers regard as rather trivial in order to perform, but nevertheless of great significance to the elderly.

The care workers in the study do, however, not accept the notion of leaving out additional services as a plausible argument for time reductions. Differentiation between defined services and additional services is a premise that they (partly) acknowledge and use in reflections on their work. Nevertheless, they find it difficult—and undesirable- to make such a clear division of services in the actual work performance. Consequently, they do not accept the explicit division between defined services and additional services in their interpretation of the consequences of economic cutbacks. They consider the cutbacks to be aiming at personal care services as a whole, stating that changes in allocation of time have not been followed by equivalent changes in the services to be performed: "There have been cutbacks (in time), but services remain the same. And that responsibility is placed with the care workers."

Care workers are left with the responsibility to adjust work performance to new temporal conditions, and the article will in the following discuss the implications relating to this strategy. Implications relate to the conceptualization of the term "additional" service. In the discussion between care workers and care managers (referred to above), the parties represent two different perspectives, managers relying on the 
standardized wording of the work schedules and care workers referring to their personal experiences with work practice. Care workers state that the term is ambiguous and holds more meaning, relating to definition as well as value and significance of services referred to. Care workers and care managers' positions reflect differences in perceptions, vocabulary, and knowledge, ultimately touching upon the fundamental understanding and conceptualization of home care. Other implications of leaving out additional services as a solution to time pressure relate to the very premises of this assumption. Care workers are (as other studies have shown) used to adjusting and adapting work performance to the overall organizational framing of work, but in this particular situation, the question naturally arises as to whether (and where) there is a limit to this practice.

\section{Avoiding splitting}

The question of which and when additional services are needed is a matter of constant consideration of the care workers. Considering the complex context of work performance, outlined in the sections above, the decision to provide additional services is generally based partly on the care worker's individual judgment of the needs, partly on a common understanding between the care worker and the elderly of the situation, and partly in consideration of the time available.

The recent political agendas of time reductions and work reorganization are, however, subjects of consideration among care workers in the study, reflecting on the possible consequences of the agendas and also in practice taking initial steps in order to adapt work performance to the new circumstances. There are in the data particular examples of care visits where care workers chose to leave out services such as washing the dishes or taking out old newspapers or the garbage of the performance, even though they seemed to be plausible tasks (considering both needs and possibilities). Care workers relate these decisions to the new agenda of leaving out additional services, arguing that they were not part of the work schedule on that particular day.

The concept of "splitting" was frequently used by the care workers in the study. Splitting (which is not a translation, as the care workers use the English term) signifies a state of dissension between the care workers, caused by different manners of conduct in work performance. Splitting is a concern which is not new to care workers, but has been reinforced by the recent debate on which services to perform. Performing additional services is still primarily a matter for the individual care worker, considering the possibilities of the unique care situation. But the recent political agenda of leaving additional services out has made care workers increasingly concerned with the possibilities of other care workers to provide the same or similar additional services. Even though it may be both possible and desirable to perform a certain task to a particular client, the care worker refrains from doing it, as it may not be possible for the next care worker who visits the client to do the same.

R: It is rewarding for me, on those days when I have some extra time, to also make the bed or to dry the hair. But it has to be with a client who is not into splitting.... (In general) you have to stick to what the schedule says, otherwise you become the good guy and your colleague becomes the bad guy. 
R: In the case I mentioned with the curlers (a situation where a client wanted her to put curlers into her hair) I have to support the group. Otherwise she would do large scale splitting. I had to say to her that I could not do it. Otherwise I would end up the favourite.

In the performance of care work and especially in relation to provision of additional services, care workers aim at applying a similar approach in order to avoid splitting. And as a consequence of striving to adapt to the agenda of leaving out additional services, discretion is undoubtedly diminished.

Still, it has to be stated that this approach of leaving out additional services constitutes a limited part of care work performance (so far). But the approach has in turn initiated a discussion among care workers, demonstrating a profound concern on whether additional services are dispensable and whether (and which) services can be characterized as additional in the first place.

\section{Indispensable care services}

Considering the complex reality of care work, care workers find the notion of separating additional services from predefined services generally simplistic and to a certain extent illegitimate. Care workers aim at approaching each care visit of the elderly from a holistic perspective, performing the tasks defined in the schedule and adding services according to the actual situation of the elderly. Applying this perspective, work performance is to a large extent directed by care workers' own judgment of the situation, deciding whenever it is necessary to supplement washing, dressing, and preparing meals with going through an official letter, assisting in shaving, checking the fridge for food, comforting, or doing some laundry, just to mention a few examples from the study, of services which can be defined as additional in the sense of not being predefined.

The temporal implications of this practice vary. The additional services may be provided in care situations, where there is a surplus of time, where the care worker has increased the pace of performance, or where other tasks are being postponed until the next day. Care workers provide what may be defined as additional services because they represent significance and value in the performance. Consequently, considering the dispensability of the single services is not only a matter of duration and significance of that single service but also a matter of how it contributes to the significance of the whole quantity of services provided during a care visit. And this point leads to yet another perspective on additional service, suggesting that the premise of dividing care services in additional and predefined is not legitimate as the label "predefined services" is inadequate to embrace what is actually taking place in care work performance.

\section{“'Do you want a bath today?'-Don't ever ask them that question"}

Using the bath as an example, this section focuses on the implementation of a predefined service, illustrating how a one-word commission ("bath") in practice involves multiple 
actions and considerations, hereby questioning the premise of labeling services as either predefined or additional.

Visiting Viggo

Viggo lives alone in an apartment. He is ill with a lung disease and very limited in moving around. When the care worker enters his home, Viggo is sitting by his kitchen table, having breakfast. According to the work schedule, Viggo has been assigned a morning package which can contain "preparing and serving breakfast, doing the dishes, preparing lunch, taking out the garbage, washing and dressing, bath." On this particular care visit, the care worker has to prepare lunch and assist Viggo in bathing. Viggo is absolutely not fond of bathing and he needs to spend time together with the care worker before he is ready for the bath. The care worker starts out by preparing lunch, and they talk about the list of groceries Viggo has to order. Then they move on to talk about the meeting he is going to attend later in the afternoon. He has been involved in local politics for many years and they discuss the recent development on social policy in the municipality. Viggo seems very engaged in these matters and expresses some sharp opinions. After a while, Viggo agrees it is time for the bath and he walks slowly to the bathroom. He is having his bath, is getting dressed, and returns to the kitchen. He continues talking about his involvement in politics, and the care worker praises him for his continuous engagement. He appreciates it, but it also gives occasion for him to regret his situation, being so limited by his illness and being so dependent on help. After yet another short while, the care worker leaves.

During the care visit, the care worker is obviously trying to adjust to the rhythms and the character of Viggo, perceiving it as a precondition for performing the task she is actually there for: assisting Viggo in bathing. Viggo has a strong will and gets easily upset. He is fond of this particular care worker, but has apparently had conflicts with several others. The care worker acknowledges that just being around Viggo, talking or performing other tasks, is necessary before and after the bath in order to make him calm and leave him in a good state.

The point of highlighting this care visit is to illustrate that a bath is not just a bath. A bath is a number of activities, including being attentive to routines and preferences of the elderly, talking, touching, dressing, and finishing up-altogether constituting the provision of a bath. As stated by Twigg, bathing is a very private matter, and aiming at recognizing the individual and private aspects of the situation, care workers have to equally persuade, show respect, distract, and care while actually performing the task.

Returning to the discussion of division of services, the example reveals the ambiguity of the bath, on the one hand being a predefined service with a premeasured duration and on the other hand being a number of activities which altogether constitute the performance of the service. Ultimately, the example illustrates that the dichotomy between predefined and additional is not valid. It is not possible to categorize all chores and tasks performed during a care visit as being either predefined or additional, as the reality of care work performance shows to be much more complex. What may (from the outside) be perceived as an additional service, as it is not being addressed in the work schedule or any other document, may well be considered as an essential part of the performance by the care worker, complicating the choice (or conceivably making the choice impossible) of leaving out "additional” services. 


\section{Is there time enough?}

Time pressure, understood as limited or insufficient time, is a problem in care work as it reduces flexibility in work performance. This problem is intensified by economic cutbacks and time reductions, having increased the focus on what home care should consist in. Care workers are told by managers to leave additional services as a way to adjust to time efficiency initiatives and reductions in time. To care workers, this is, however, a simplistic notion, not corresponding with the complex character of care work. This study has identified three perspectives on the concept of service division: 1) that additional services can be identified and left out, 2) that additional services can be identified, but are indispensable, and 3) that division of services is not recognized. To a certain extent, care workers recognize that they include actions or services which can be characterized as additional in work performance, and the study has shown that some care workers have taken initial steps in terms of adjusting their performance to the request on leaving out additional service. In many care situations though, care workers may find it possible, but not preferable, to leave out services from performance, as they find these services essential in their overall perception of the meaningful care work. In relation to yet other care situations, care workers do not accept the notion of service division at all. Rather, they perceive their performance of work in a more holistic perspective, emphasizing how the services are provided and the performance carried out.

Relating this dilemma with the perspectives on service division, represented by Dyck and England and Kirchhoff, the findings of this study show that neither does it make sense in practice to categorize services as either predefined or additional nor is it adequate to categorize services according to their practical and emotional character. On the contrary, this study has revealed that there is a huge overlap of practical and emotional aspects in the provision of the particular services-a combination which is essential to care workers in terms of constituting a holistic and meaningful care work performance.

The issue of service division reveals two opposite positions, care managers relying on the word of the work schedules and care worker relying on their experiences with transforming the work schedule into practice, representing different views on both the content and meaning of home care work. The theoretical perspectives on standardization and on care in private homes are reflected in the two positions. As they together illustrate the complexity of care work performance, indications are that time pressure elucidates the differences between the two, reducing care workers' flexibility and possibilities to perform the work in a meaningful way.

This development could be understood in the light of a more fundamental dilemma in the welfare state organization, concerning the discrepancy between welfare state ambitions and the output capacity. In the care organization, this dilemma is most distinct to the care workers, being the embodiment of the welfare state in the meeting with the elderly. Political considerations on making the organization more efficient are seldom related to knowledge of the actual care work, and the consequences of political/administrative decisions "are seldom available for the experience of the decision makers" (Vike $\&$ Bakken 2002). More researchers have pointed to the fact that the central dilemma is being decentralized, making care workers responsible for implementing political decisions on universal care as well as responsible for performance of good care for the single citizen (Rasmussen 2004; Vike \& Bakken 2002). 
Viewing the problem in a reverse perspective, care work performance is a complex phenomenon which is not articulated in the standardized definitions of care work. It is instead characterized by care workers giving content to a predefined temporal framing and predefined standardized services, stressing care workers' flexibility and responsibility in performance, but also their great dependence on time. When the temporal frame of performance is limited, flexibility is reduced, authority is challenged, but responsibility remains. The battle on time has to be fought according to the terminology of standardization (arguing for a certain amount of time for a certain task), but ultimately the limited time constitutes a pressure on performance as a whole.

Consequently, there may not be an unambiguous answer to the question of whether there is time enough, but the significance of time is, in turn, clearly exposed. The study has shown that time is imperative in order to maintain flexibility in work performance and, on the contrary, that lack of time interferes with care workers' perception of the meaningful care work, exposing the ambiguity of the conceptualization of home care. Stating that "We may agree on the services, but we do not agree on the time," care workers indicate that they do not disagree with care managers (and other actors on the administrative and political levels) on which care services to perform. Problems arise in relation to the question of how they should be performed, ultimately revealing the battle on time as an expression of the fundamental ambivalences in care work.

\section{References}

Adam, B. (1990) Time and Social Theory. Cambridge: Polity Press.

Adam, B. (1995) Timewatch: The Social Analysis of Time. Cambridge: Polity Press.

Alvesson, M. and Sköldberg, K. (2000) Reflexive Methodology-New Vistas for Qualitative Research. London: Sage Publications.

Andersson, K. (2008) The Neglect of Time as an Aspect of Organising Care Work, in Wrede, S. e. a. (ed.): Care Work in Crisis. Malmö: Studentlitteratur, 342-361.

Bjôrnsdottir, K. (2012) Assisting the Frail Elderly to Live a Good Life Through Home Care Practice, in Ceci, C., Bjornsdottir, K., and Purkis, M. E. (eds.): Perspectives on Care at Home for Older people. NewYork: Routledge, 121-135.

Bryson, V. (2007) Gender and the Politics of Time: Feminist Theory and Contemporary Debates. Bristol: The Policy Press.

Burau, V. and Dahl, H. M. (2013) Trajectories of Substantive Change in Danish Long-Term Care Policies, in Ranci, C. and Pavolini, E. (eds.): Reforms in Long-Term Care Policies in European Countries. New York: Springer, 79-95.

Charmaz, K. (2003) Grounded Theory, in Smith, J. A. (ed.): Qualitative Psychology. London: Sage Publications, 81-109.

Charmaz, K. (2006) Constructing Grounded Theory: A Practical Guide Through Qualitative Analysis. London: Sage Publications.

Cohen, R. L. (2011) Time, space and touch: body work and labour process (re)organization, Sociology of Health and Illness 33(2): 189-205.

Dahl, H. M. (2009) New Public Management, care and struggles about recognition, Critical Social Policy 29(4): 634-654.

Dahl, H. M. and Rasmussen, B. (2011) Paradoxes in Elderly Care: The Nordic Model, in Kamp, A. and Hvid, H. (eds.): Elderly Care in Transition-Management, Meaning and Identity at Work. A Scandinavian Perspective. Copenhagen Business School Press, 29-50.

Davies, K. (1994) The tensions between process time and clock time in care-work, Time \& Society 3(3): 277-303. 
Dyck, I. and England, K. (2012) Homes for care: Reconfiguring Care Relations and Practices, in Ceci, C., Bjornsdottir, K., and Purkis, M. E. (eds.): Perspectives on Care at Home for Older People. New York: Routledge, 62-77.

Eriksen, T. H. (2002) Øjeblikkets tyranni. Copenhagen: Tiderne Skifter. (In English: Tyranny of the Moment.)

Fine, G. A. (1990) Organizational time: temporal demands and the experience of work in restaurant kitchens, Social Forces 69(1): 95-114.

Flybbjerg, B. (1991) Rationalitet og magt. Copenhagen: Akademisk Forlag. (In English: Rationality and Power.)

Halkier, B. (2002) Fokusgrupper. Frederiksberg: Samfundslitteratur. (In English: Focus Groups.)

Kirchhoff, J. (2010) De skjulte tjenestene-om uønsket atferd i offentlige organisasjoner. Karlstad University. Faculty of Economic Sciences, Communication and IT, Working Life Science. (In English: The Hidden Services-About Unwanted Behaviour in Public Organisations.)

Mol, A. (2008) The Logic of Care: Health and the Problem of Patient Choice. New York: Routledge.

Neergaard, H. (2007) Udvelgelse af cases $i$ kvalitative undersøgelser. Frederiksberg: Samfundslitteratur. (In English: Selection of Cases in Qualitative Studies.)

Purkis, M. E., Ceci, C. and Bjornsdottir, K. (2008) Patching up the holes: analyzing the work of home care, Canadian Journal of Public Health 99(Supplement 2): s27-s32.

Rasmussen, B. (2004) Between endless needs and limited resources: the gendered construction of a greedy organization, Gender Work and Organization 11(5): 506-525.

Steyaert, C. and Bouwen, R. (2004) Group Methods of Organizational Analysis, in Cassell, C. and Symon, G. (eds.): Essential Guide to qualitative Methods in Organizational Research. London: Sage Publications, 140-153.

Strauss, A. and Corbin, J. (1998) Basics of Qualitative Research. Thousand oaks, California: Sage Publications.

Timmermans, S. and Almeling, R. (2009) Objectification, standardization, and commodification in health care: a conceptual readjustment, Social Science \& Medicine 69(1): 21-27.

Timmermans, S. and Epstein, S. (2010) A World of Standards but Not a Standard World: Toward a Sociology of Standards and Standardization. Palo Alto: Annual Reviews.

Trydegård, G.-B. (2012) Care work in changing welfare states: Nordic care workers' experiences, European Journal of Ageing (9): 119-129.

Twigg, J. (1997) Deconstructing the "social bath": help with bathing at home for older and disabled people, Journal of Social Policy 26: 211-232.

Twigg, J. (1999) The spatial ordering of care: public and private in bathing support at home, Sociology of Health and Illness 21(4): 381-400.

Twigg, J. (2000) Bathing: The Body and Community Care. London: Routledge.

Vabø, M. (2007) Organisering for velferd-Hjemmetjenesten $i$ en styringsideologisk brytningstid. Oslo: NOVA-Norsk institutt for forskning om oppvekst, velferd og aldring. (In English: Organising for Welfare-Home Care Service in a Time of Fermentation, Characterized by Management Ideology).

Vike, H. and Bakken, R. (2002) Maktens samvittighet: om politikk, styring og dilemmaer $i$ velferdsstaten. Oslo: Gyldendal Akademisk. (In English: The Consciousness of Power: About Politics, Governance and Dilemmas in the Welfare State.)

Waddington, D. (2004) Participant Observation, in Cassell, C. and Symon, G. (eds.): Essential Guide to Qualitative methods in Organizational Research. London: Sage Publications, 154-164.

Waerness, K. (1984) The rationality of caring, Economic and Industrial Democracy 5(2): $185-211$. 